\title{
HIV-1 Clade-Specific Differences in the Induction of Neuropathogenesis
}

\author{
Vasudev R. Rao, ${ }^{1}$ Andrew R. Sas, ${ }^{3}$ Eliseo A. Eugenin, ${ }^{2}$ Nagadenahalli B. Siddappa,${ }^{4}$ Heather Bimonte-Nelson, ${ }^{5}$ \\ Joan W. Berman, ${ }^{1,2}$ Udaykumar Ranga, ${ }^{4}$ William R. Tyor, ${ }^{3}$ and Vinayaka R. Prasad ${ }^{1}$ \\ Departments of ${ }^{1}$ Microbiology and Immunology and ${ }^{2}$ Pathology, Albert Einstein College of Medicine, Bronx, New York 10461, ${ }^{3}$ Medical University of South \\ Carolina, Charleston, South Carolina 29425, ${ }^{4}$ Jawaharlal Nehru Centre for Advanced Scientific Research, Bangalore 560 064, India, and ${ }^{5}$ Department of \\ Psychology, Arizona State University, Tempe, Arizona 85287
}

Human immunodeficiency virus (HIV)-associated dementia (HAD) is common among clade B HIV-infected individuals, but less common and less severe among individuals infected with clade C HIV-1, suggesting clade-specific differences in neuropathogenicity. Although differences in neuropathogenicity have been investigated in vitro using viral proteins responsible for HAD, to date there are no virological studies using animal models to address this issue. Therefore, we investigated neuropathogenesis induced by HIV-1 clades using the severe combined immune deficiency (SCID) mouse HIV encephalitis model, which involves intracranial injection of macrophages infected with representative clade $\mathrm{B}\left(\mathrm{HIV}-1_{\mathrm{ADA}}\right)$ or clade $\mathrm{C}\left(\mathrm{HIV}-1_{\text {Indie-C1 }}\right) \mathrm{HIV}-1$ isolates into SCID mice. In cognitive tests, mice exposed to similar inputs of HIV-1 clade C made fewer memory errors than those exposed to HIV-1 clade B. Histopathological analysis of mice exposed to clade B exhibited greater astrogliosis and increased loss of neuronal network integrity. In vitro experiments revealed differences in a key characteristic of HIV-1 that influences HAD, increased monocyte infiltration. HIV-1 Indie-C1 $_{1}$-infected macrophages recruited monocytes poorly in vitro compared with $\mathrm{HIV}-1_{\mathrm{ADA}}$-infected macrophages. Monocyte recruitment was HIV-1 Tat and CCL2 dependent. This is the first demonstration, ever since HIV neuropathogenesis was first recognized, that viral genetic differences between clades can affect disease severity and that such studies help identify key players in neuropathogenesis by HIV-1.

Key words: dementia; human; virus; cognitive; lentiviruses; macrophage

\section{Introduction}

Human immunodeficiency virus (HIV)-associated dementia (HAD) affected 15-30\% of infected individuals before the widespread use of highly active antiretroviral therapy (HAART) in the United States (McArthur et al., 1993). Despite reduced HAD incidence with the advent of HAART (Sacktor et al., 2001; Dore et al., 2003), improved survival rates of HIV-infected individuals have led to increase in cognitive impairment resulting from chronic CNS HIV exposure (Sacktor et al., 2001; Langford et al., 2003). In contrast, incidence/prevalence of severe forms of HAD is reported to be considerably lower $(2-4 \%)$ in the HAART-naive HIV-1-infected population in India, although milder forms of

\footnotetext{
Received June 26, 2008; accepted Aug. 28, 2008.

This work was supported by Public Health Service Research Grants R21 MH075636 and R01 MH083579 (V.R.P.), as well as a capacity building grant (D43 TW001403) from the Fogarty International Center-National Institutes of Health (NIH) that bridged the transnational collaboration (program director, V.R.P.). A.R.S. was supported by an NIH predoctoral fellowship (F31 NS054592), and E.A.E. was supported by a mentoring grant (K01 MH076679). Housing of mice at the Medical University of South Carolina was partially supported by NIH Grant CO6 RR015455. We thank the Einstein/Montefiore Center for AIDS Research for the use of Immunology/Pathology and BSL3/Clinical Virology Core services, Albert Einstein Cancer Center for the use of the Histopathology Core, and Adam Davis for reading this manuscript.

The authors declare no competing financial interests.

This article is freely available online through the J Neurosci Open Choice option.

Correspondence should be addressed to Dr. Vinayaka R. Prasad, Department of Microbiology and Immunology, Albert Einstein College of Medicine, 1300 Morris Park Avenue, Bronx, NY 10461. E-mail: prasad@aecom.yu.edu.

N. B. Siddappa's present address: Department of Cancer Immunology and AIDS, Dana-Farber Cancer Institute, Harvard Medical School, Boston, MA 02115

DOI:10.1523/JNEUROSCI.2955-08.2008

Copyright $\odot 2008$ Society for Neuroscience $\quad 0270-6474 / 08 / 2810010-07 \$ 15.00 / 0$
}

disease have been reported (Satishchandra et al., 2000; Riedel et al., 2006; Gupta et al., 2007). The Indian acquired immunodeficiency syndrome (AIDS) epidemic is dominated by clade $\mathrm{C}$ HIV-1 (Chakrabarti et al., 2000; Siddappa et al., 2004) and the clade C HIV-1 is found in brain autopsies (Mahadevan et al., 2007) from HIV-infected Indian patients suggesting a cladespecific difference in the neuropathogenesis of HIV-1. Clade C HIV-1 is responsible for more than half of new HIV-1 infections worldwide (Geretti, 2006) and a major proportion of HIV infections in India (Siddappa et al., 2004), whereas in North America, HIV-1 clade B is responsible for nearly all HIV-1 infections.

Mechanisms underlying the pathogenesis of HAD, characterized by neuronal injury, are complex, including infiltration of monocyte-derived macrophages (MDMs) into brain and neurotoxic effects of HIV-1 proteins (e.g., gp120 and Tat). Tat plays multiple roles in $\mathrm{HAD}$ pathogenesis, including direct neurotoxicity (Gourdou et al., 1990; Sabatier et al., 1991), chemokine dysregulation (Conant et al., 1998; Weiss et al., 1999), and cytokine induction. A dicysteine motif in Tat has been implicated in direct monocyte chemotaxis in vitro (Albini et al., 1998). We previously reported that clade $\mathrm{C}$ Tat is divergent from other HIV-1 clades in that the dicysteine motif (C30C31), which is highly conserved in all clades examined, exhibits a C31S polymorphism (Ranga et al., 2004), rendering it defective for monocyte chemotaxis in vitro.

Differential distribution of B and C HIV-1 clades and differences in host genetics and access to antiretrovirals make it diffi- 
cult to assess neuropathologic differences between populations infected by B and C HIV-1 clades. These difficulties are largely overcome by the use of the severe combined immune deficiency mouse HIV encephalitis (SCID HIVE) model (Tyor et al., 1993; Persidsky et al., 1996), in which for the first time the two HIV-1 clades are compared in a single host. This model involves intracranial injection of MDMs infected by HIV-1 into SCID mice, and its strength lies in its ability to recapitulate key pathological and behavioral features of human HAD (Avgeropoulos et al., 1998; Cook et al., 2005). Importantly, these mice also exhibit behavioral deficits when tested in a water radial arm maze (WRAM) (Avgeropoulos et al., 1998; Sas et al., 2007), which are consistent with cognitive dysfunction in human HAD. In this report, we primarily investigate neuropathogenic differences of clade B and clade C HIV-1 isolates. We find that neuropathogenesis by a clade $\mathrm{C} \mathrm{HIV-1}$ results in a milder cognitive dysfunction than with a clade B HIV-1. We also show that (1) HIV-infected MDMs or the media from such cells can recruit monocytes; (2) that monocyte recruitment is Tat and CCL2 dependent; and (3) that clade C HIV-1 is significantly compromised for monocyte chemotaxis. Our work shows that both direct and indirect effects of HIV-1 Tat protein are compromised in subtype C HIV-1 in a virological setting.

\section{Materials and Methods}

HIV-1 infection, animals, and behavioral testing. Primary human MDMs (purchased from the University of Nebraska Medical Center) were cultured in DMEM (Invitrogen) with 10\% human serum (Sigma), penicillinstreptomycin (Invitrogen), and macrophage colony-stimulating factor (MCSF; Sigma) at $6.6 \mathrm{ng} / \mathrm{ml}$ at $37^{\circ} \mathrm{C}$ with $5 \% \mathrm{CO}_{2}$ for $7 \mathrm{~d}$ in Teflon-coated flasks to prevent attachment. To ensure that the HIV-infected MDMs used for intracranial injection had equivalent viral loads, $\sim 5 \times 10^{6} \mathrm{MDMs}$ were infected with $\mathrm{HIV}-1_{\mathrm{ADA}}$ (clade B) at a multiplicity of infection (MOI) of 0.1 $(1 \mathrm{~h})$ or HIV-1 $1_{\text {Indie-Cl }}$ (clade C) at an MOI of 0.01 ( $3 \mathrm{~h}$ ). HIV-1 $1_{\mathrm{ADA}}$ was obtained from the University of Nebraska Medical Center, and HIV$1_{\text {Indie-C1 }}$ was prepared by transfecting $293 \mathrm{~T}$ cells with p93IN101 DNA (Mochizuki et al., 1999). Uninfected MDMs were used as controls. After infection, MDMs were resuspended in medium devoid of M-CSF and cultured for $14 \mathrm{~d}$ with media changes every third day. At the end of $14 \mathrm{~d}$ incubation, both sets of MDMs displayed similar viral load as determined by immunocytochemistry with anti-p24 antibodies (DAKO) and ELISA to measure p24 levels in the media (PerkinElmer Life and Analytical Sciences) (see Fig. 2). MDMs, grown in Teflon-coated flasks, are recovered by centrifugation and resuspended in PBS for inoculation into mice.

Eighteen 4-week-old C57BL SCID mice (Jackson Laboratory) were acclimatized to the animal room for 1 week before injection. Mice were single-housed in microisolator cages (biosafety level-3 equivalent). The animal room was set on a $12 \mathrm{~h}$ light cycle. Cages, bedding, food, and water were sterilized before use. Animal protocols were approved by the Medical University of South Carolina's Institutional Animal Care and Use Committee. Approximately $1 \times 10^{5} \mathrm{HIV}$-1-infected MDMs (clade B or C) or uninfected MDMs were injected into the right frontal lobe of 5 -week-old SCID mice ( $n=6$ per group). Six days after intracranial injections, WRAM behavior testing ensued. This win-shift WRAM uses water escape onto hidden platforms as the reinforcer (Hyde et al., 1998; Bimonte-Nelson et al., 2003; Hunter et al., 2004). The eight-arm maze had submerged escape platforms placed on the ends of four arms. Each subject had different platform locations that remained fixed throughout the experiment. A subject was released from the start arm and had $2 \mathrm{~min}$ to locate a platform. Once a platform was found, the mouse remained on it for $15 \mathrm{~s}$, and was then returned to its heated cage for $30 \mathrm{~s}$ until the next trial. During the interval, the platform found by the mouse was removed from the maze. The animal was then placed again into the start alley and allowed to locate a second platform. The same sequence of events was repeated daily until all four platforms were located. Thus, for each animal, a daily session consisted of four trials, with the number of plat- formed arms reduced by one on each subsequent trial, resulting in the working memory system becoming increasingly demanding as trials progressed. Animals received 4 trials/d for $12 \mathrm{~d}$. The testing protocol included an initial learning phase (days 1-8) and a final testing phase (days 9-12). Working memory correct (WMC) and working memory incorrect (WMI) errors were quantified based on the orthogonal measures of Jarrard and others (Jarrard, 1993; Hyde et al., 1998; Bimonte-Nelson et al., 2003; Hunter et al., 2004). WMC errors were defined as entries into an arm wherein a platform had already been located, and WMI errors were defined as repeat entries into an arm that never contained a platform.

Immunohistochemistry, densitometry, and detection of HIV RNA levels using real-time PCR. After WRAM testing, mice were killed and brains extracted and frozen for immunohistochemistry $(n=6)$. Approximately 13 sets of serial $5 \mu \mathrm{m}$, coronal sections were taken from the frontal through the temporoparietal lobes of each mouse. Each set was separated by 46 intervening $5 \mu \mathrm{m}$ sections, which were saved for RNA extraction. Each stained set consisted of slides that underwent immunoperoxidase staining separately for human macrophages (EBM-11; Dako); HIV-1 p24 (p24; DAKO); astrocytes (GFAP; Millipore Bioscience Research Reagents) and neuronal dendrites (MAP2; Millipore Bioscience Research Reagents) as described previously (Avgeropoulos et al., 1998; Sas et al., 2007). Average numbers of primary human macrophages (EBM-11positive cells) and HIV-infected cells (p24 positive cells) were determined by light microscopy. Immunoperoxidase-stained slides were imaged at $20 \times$ using an Olympus microscope. Densitometry analysis was performed to determine the intensity of immunoperoxidase stain using $\mathrm{NIH}$ Image software on the images $(20 \times)$ representing sections stained for astrogliosis (GFAP) and neuronal network integrity (MAP2) (Sas et al., 2007). For measuring neuronal integrity (MAP2), the left hemisphere (noninjected hemisphere) of each mouse served as a normal control and was set at $100 \%$. The measured value of the right hemisphere was compared with the left hemisphere of the section to determine the relative differences in MAP2 staining. Three sections per mouse from six mice per group were analyzed in the above manner to derive the final values plotted in Figure 3.

For real-time PCR measurements of viral RNA, the tissue from these intervening sections was homogenized, and the RNA was extracted according to the RNAwiz (Ambion) protocol. Approximately $1 \mu \mathrm{g}$ of total RNA was used for cDNA synthesis. First-strand cDNA synthesis was performed using the High Capacity cDNA Archive kit (Applied Biosystems). HIV-1 gag RNA levels were determined using real-time PCR with ABI 7000 Prism (Applied Biosystems) to determine viral load, according to the manufacturer's suggested protocol.

Measurement of monocyte migration using a dual-chamber assay. Human MDMs were cultured for $4 \mathrm{~d}$ under the same conditions as described above. Approximately $2 \times 10^{5} \mathrm{MDMs}$ were plated in the lower wells of a 24 -well plate (Rao et al., 2009). Approximately $2 \times 10^{5}$ cultured MDMs were infected with $\mathrm{HIV}-1_{\mathrm{ADA}}$ virus (clade B) at an MOI of 0.1 for $1 \mathrm{~h}$ or $\mathrm{HIV}-1_{\text {Indie-C1 }}$ (clade C) at an MOI of 0.01 for $3 \mathrm{~h}$ and incubated for $5 \mathrm{~d}$ in the above-mentioned medium devoid of M-CSF. ELISA for p24 in the supernatant staining and p24 staining of macrophages were used to ensure equal viral load for both $\mathrm{HIV}-1_{\mathrm{ADA}}$ and $\mathrm{HIV}-1_{\text {Indie-Cl }}$. In the upper chamber, $2 \times 10^{5}$ elutriated human monocytes were added. To facilitate their identification subsequent to migration, monocytes were stained with carboxyfluorescein succinimidyl ester (CFSE) dye before adding them to the transwells. After $24 \mathrm{~h}$ of incubation, cells in the lower chamber were examined in a fluorescence microscope to quantify the migrated cells.

Neutralization of Tat and CCL2 proteins. Neutralization of Tat and CCL2 proteins was performed by a slightly modified version of the earlier technique (Weiss et al., 1999). Four days after HIV-1 infection, the infected MDMs, prepared the same way as described in the migration experiments, were incubated with fresh medium (DMEM $2 \%$ human serum) for $24 \mathrm{~h}$ (Rao et al., 2009). The conditioned medium (supernatant from HIV-1-infected and control wells) was then incubated for $1 \mathrm{~h}$ with Pansorbin beads (EMD Biosciences) to which either anti-Tat [E1.1, which neutralizes both Tat proteins (U. Ranga, unpublished observations)] or anti-CCL2 antibodies (MAb 279; R\&D Systems) were prebound. Optimal antibody concentrations were determined for Tat by testing increasing concentrations of antibodies and for CCL2 based on the CCL2 levels in the medium determined by ELISA. Beads were re- 
moved by pelleting, and the supernatant was used in migration experiments following the above-mentioned migration protocol.

Tat-induced and HIV infection-induced secretion of CCL2 from MDMs and astrocytes. Four days after HIV infection, MDMs were incubated for $24 \mathrm{~h}$ in fresh medium without human serum to eliminate the contribution of CCL2 in human serum. The day 5 no-serum supernatant was collected, and ELISA for CCL2 (R\&D Systems) was performed in triplicates in three separate experiments as described previously (Eugenin et al., 2006)

Statistical analysis. Statistical analysis for the behavior study was via StatView. Repeatedmeasures ANOVA analysis was performed, and the $p$ values were obtained by comparing errors made by clade $\mathrm{B}$, clade $\mathrm{C}$, and control mice individually with each other. For migration studies, chemokine expression, and histopathology analysis, the significance and $p$ values were determined using Microsoft Excel.

\section{Results}

SCID mice with clade C HIV-1 display milder cognitive deficits than clade $B$ HIV SCID mice

The SCID mouse HIV encephalitis model, developed originally by Tyor et al. (1993) and subsequently improved by both W. Tyor and coworkers and H. Gendelman and coworkers, is a useful, sensitive, and well characterized animal model to test HIV-induced neurotoxicity and behavioral changes (Persidsky et al., 1996, 1997; Avgeropoulos et al., 1998; Cook et al., 2005; Sas et al., 2007). Behavioral testing with WRAM revealed that clade B HIVE mice exhibited poor working memory as shown on two orthogonal measures of working memory competence. Clade B HIVE mice made more WMI (a form of long-term memory) and WMC (a form of short-term memory) errors when compared with controls (Fig. 1). Repeated-measures ANOVA to analyze the number of errors, which were collapsed across testing days (days 9-12) and trials, revealed that clade B HIVE mice made significantly more WMI errors than clade C HIVE mice $(p=0.046)$ (Fig. 1a) or the controls $(p=0.005)$ (Fig. 1a) injected with uninfected MDMs. Clade B HIVE mice made significantly more WMC errors than the controls $(p=0.042)$ (Fig. 1b). Clade C HIVE mice made an intermediate number of WMI errors between clade B and the controls (Fig. 1b). Moreover, clade B HIVE mice were less successful in handling an increasing working memory load as shown on two dependent variables. Indeed, clade B HIVE mice made significantly more WMC and WMI errors than clade C HIVE or the control mice as the memory load increased during the later trials (Fig. $1 c, d$ ).

Brains of SCID mice exposed to either HIV-1 clade B or HIV1 clade $\mathrm{C}$ show similar viral loads, but those with clade $\mathrm{C}$ HIV-1 show decreased pathology

Evaluating different clades of HIV-1 for their potential to induce SCID HIVE requires that the viral load of these related, but distinct, viruses are comparable. Therefore, in addition to ensuring that the MDMs injected into mouse brain contained equal proportions of HIV-positive cells with similar viral replication (Fig. 2 ), immunohistochemical analysis of the frozen sections was per- b.
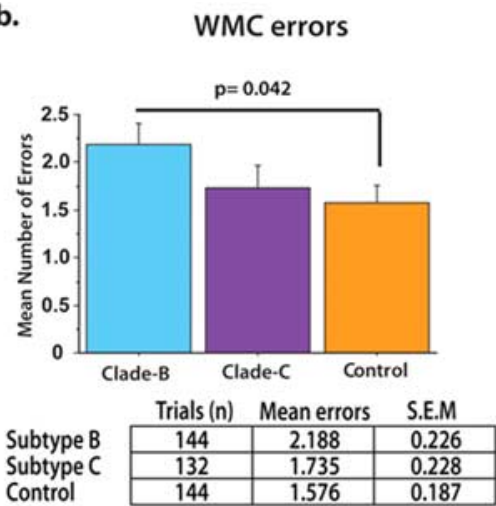

d.

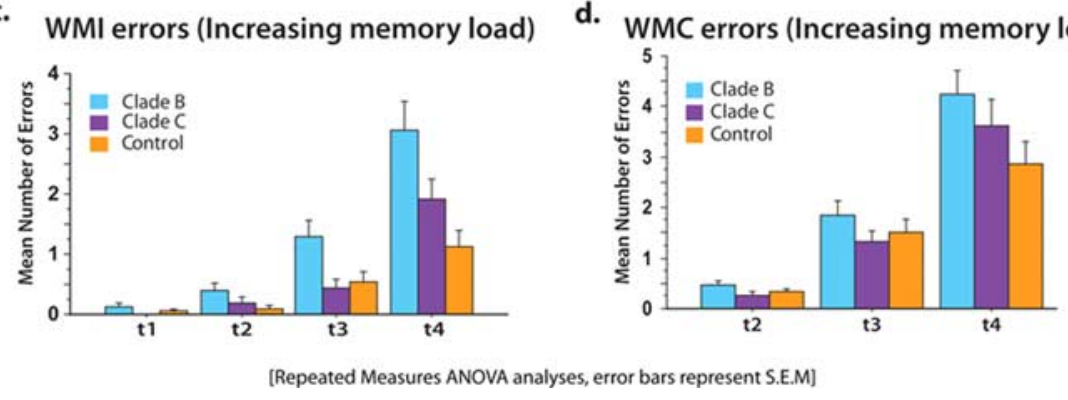

[Repeated Measures ANOVA analyses, error bars represent S.E.M]

ad)

Figure 1. Cognitive performance of HIV-infected and control SCID mice in the latter phase of testing. $\boldsymbol{a}, \boldsymbol{b}$, Cognitive performance of HIV-infected and control mice averaged across days (9-12) and trials [1- 4 trials for WMI (a form of long-term memory; errors, respectively, for each trial for the latter phase of testing. Clade B HIVE mice were less successful at handling increasing working memory load with two dependent variables. t1-t4, Trials 1-4.

formed with antibodies to HIV-1 p24 (Fig. 2). This analysis showed equal numbers of HIV-positive cells in the brains of SCID mice infected with either virus $[11 \pm 4$ vs $13 \pm 5$ (mean \pm SD) p24-positive cells per section for clade B and clade C HIVinfected SCID mouse brains, respectively; the data represent an average of five sections per mouse brain around the injection site in the frontal cortex region and nine mice in each group]. Quantitative reverse transcription-PCR analysis of HIV-1 clade B- and clade C-infected mouse brains ( $n=6$; from frontal cortex) revealed average log copy numbers of $12.75 \pm 0.11$ and $12.36 \pm$ 0.16 (mean \pm SEM), respectively (Fig. 2).

Astrogliosis, as evidenced by GFAP staining, and a decrease in neuronal network integrity, as indicated by reduction in MAP2 staining, were observed in the brains of mice injected with HIVinfected MDMs in frontal lobe sections around the injection tract. Brains of control mice also displayed low levels of astrogliosis and a slight reduction in MAP2 staining, suggesting background inflammation. However, the severity of astrogliosis in the frontal cortex region was greatest in clade B HIV-infected SCID mice (Fig. $3 a)$ compared with clade C HIVE $(p=0.0117)$ and control ( $p=0.0008)$ mice. Percentage MAP2 staining comparing the right and the left frontal cortex regions for neuronal integrity revealed a significant difference between brains of mice injected with clade B HIV-1 and control brains $(p=0.0006)$ but no statistically significant differences between the two HIV-1 clades (Fig. 3b). Nevertheless, a trend for less severe MAP2 changes was observed in clade C HIVE mice compared with clade B HIV-1 HIVE mice. 
a.

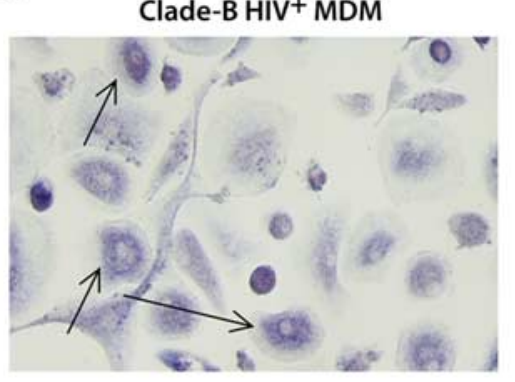

b. Clade-B HIV+ Mouse Brain

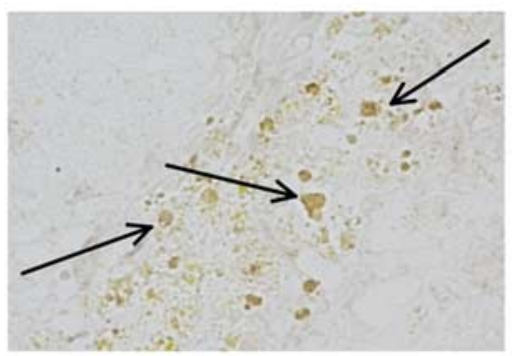

Clade-C HIV+ MDM

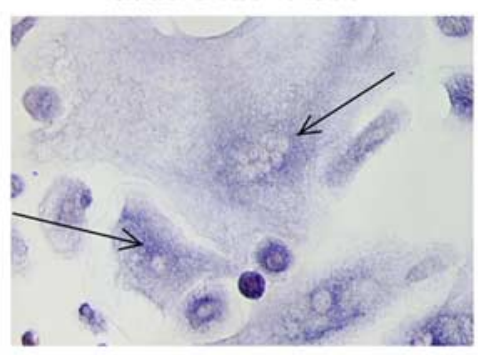

Clade-C HIV+ Mouse Brain

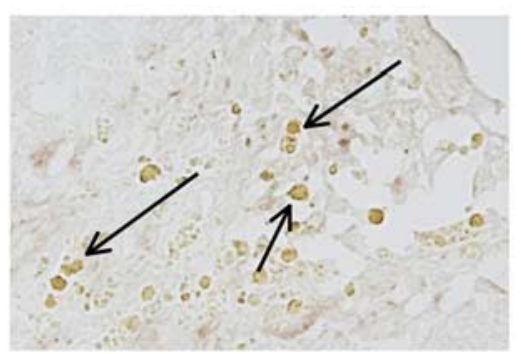

c.

\begin{tabular}{|l|c|c|}
\hline p24 +ve cells (MDM) & $44 \% \pm 3 \%$ (S.D) & $40 \% \pm 4 \%$ (S.D) \\
\hline p24 +ve cells (Brain Sections) & $11 \pm 4$ cells/sec (S.D) & $13 \pm 5$ cells/sec (S.D) \\
\hline RT-PCR Analysis (Avg Log Copy No.) & $12.75 \pm 0.11$ (S.E.M) & $12.36 \pm 0.16$ (S.E.M) \\
\hline
\end{tabular}

Figure 2. In vitro and in vivo quantitation of viral infectivity in injected MDMs and infected mouse brains. $\boldsymbol{a}$, HIV -1 p24 immunostaining of clade B and clade C HIV-infected MDMs in culture before injecting into mouse brain. The p24-positive cells are stained dark to medium blue (shown by black arrows). $\boldsymbol{b}$, p24 immunostaining of frontal cortex sections of clade B and clade $C$ HIV-infected mouse brains along the injection track $17 \mathrm{~d}$ after injection. Arrows point to some of the p24-positive cells. $c$, Quantitation of HIV-infected cell numbers from $\boldsymbol{a}$ and $\boldsymbol{b}$ as well as the viral RNA copy numbers in frontal cortex of mouse brains as determined by real-time $P C R$ with clade-specific primers and probes. The results show that the viral load for each clade of HIV- 1 is similar both in the infected MDMs before injection and $17 \mathrm{~d}$ after injection in the brains of mice.
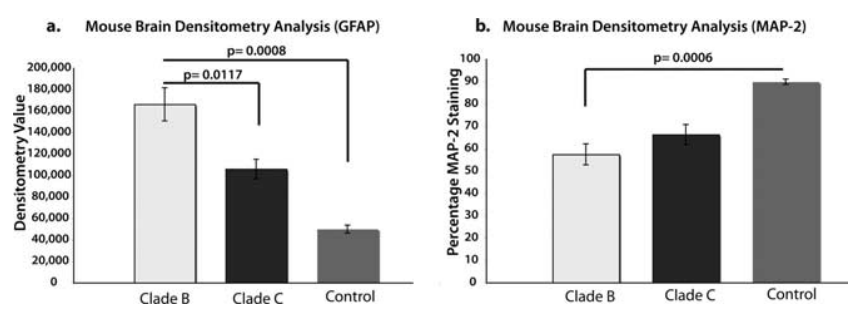

Figure 3. Quantitative assessment of immunoperoxidase-stained sections of HIV-infected and control mouse brains. $\boldsymbol{a}$, Measurement of GFAP-positive cells to determine astrogliosis. Densitometric analysis of five frontal cortex GFAP-stained sections from the brains of six mice in each group injected with uninfected, clade B HIV-infected, and clade C HIV-infected MDMs at $17 \mathrm{~d}$ after injection. $\boldsymbol{b}$, Measurement of MAP2-positive cells to examine neuronal network integrity [from 3 sections per mouse $(n=6)$ around the site of injection in the frontal cortex and comparing the right hemisphere to the left] at $17 \mathrm{~d}$ after injection. Clade C HIVE mice show distinctly lower astrogliosis than clade B HIVE mice, while showing an intermediate loss of MAP2 stain between clade B HIVE mice and control mice. Error bars represent SEM.

\section{Clade C HIV-infected MDMs display reduced monocyte chemotaxis}

Monocyte infiltration into the brain is a hallmark of HAD. Although Tat causes monocyte chemotaxis in vitro, monocyte chemotaxis by Tat in the context of HIV-infected cells has not been demonstrated. To investigate clade differences in monocyte chemotaxis, we used MDMs, HIV-1 susceptible cells that are relevant to HIV-1 neuropathogenesis, that were infected with either HIV$1_{\mathrm{ADA}}$ (clade B) or HIV-1 $1_{\text {Indie-C1 }}$ (clade C). HIV-infected MDMs

were added to the bottom chamber of the transwell system, and elutriation-derived, undifferentiated human monocytes were added to the top chamber (Rao et al., 2009). After $24 \mathrm{~h}$ of incubation, we observed that clade B-infected MDMs attracted $64 \%\left(p=3.5 \times 10^{-5}\right)$ more monocytes than did clade C-infected MDMs (Fig. 4a). Supernatant p24 ELISA (PerkinElmer Life and Analytical Sciences) measurements were done before the migration experiments to ensure that the two sets of MDM cells had similar viral loads.

\section{Chemotaxis induced by HIV-infected MDMs is mediated by Tat and CCL2} HIV-infected MDMs secrete a number of soluble factors into the medium, including Tat protein. To delineate the contribution of factors influencing monocyte chemotaxis, the medium from infected MDM cell culture was first confirmed to induce chemotaxis using the in vitro dual-chamber assay described earlier (Fig. $4 b$, no treatment). Then, to determine whether extracellular Tat plays a role in chemotaxis, the medium was immunodepleted using antiTat neutralizing antibodies. These experiments demonstrated that a greater proportion of monocytes recruited by clade $B$ HIV-infected MDMs were attributable to Tat compared with clade C HIV-infected MDMs. Similarly, immunodepletion of CCL2 revealed that CCL2 also plays a key role in monocyte chemotaxis caused by infection by either clade of HIV-1 (Fig. $4 b$ ).

\section{Poor induction of CCL2 chemokine by clade C HIV-1 and its Tat protein}

Tat released from infected cells can gain access into uninfected cells in the vicinity (Schwarze et al., 1999). A transcriptional transactivator of both viral and cellular genes, Tat induces astrocytes and monocytes in vitro to produce chemokines (e.g., CCL2) (Conant et al., 1998; Weiss et al., 1999; D’Aversa et al., 2004). Therefore, we investigated the mechanistic basis for lowered monocyte chemotaxis by clade $\mathrm{C}$ Tat protein. We measured the production of CCL2 by monocytes and astrocytes after the addition of Tat protein from either clade to cultures for $24 \mathrm{~h}$. Clade C Tat protein, compared with clade B Tat, induced significantly lower levels of CCL2, in a dose-dependent manner, in both MDMs (100 ng of Tat, $p=1.4 \times 10^{-5} ; 500 \mathrm{ng}$ of Tat, $p=6.1 \times$ $10^{-10}$ ) and astrocytes (100 ng of Tat, $p=0.0017 ; 500 \mathrm{ng}$ of Tat, $p=0.0001)($ Fig. 5a,b).

To test the relevance of this finding in the context of HIV-1 replication, we measured the secretion of CCL2 by clade B and C HIV-1-infected MDMs. HIV-infected MDMs were incubated for $24 \mathrm{~h}$ in serum-free medium to eliminate the confounding presence of CCL2 in human serum used for growing MDMs. Clade C HIV-infected MDMs displayed a significantly reduced ability to secrete CCL2 in comparison with clade B-HIV-infected MDMs $(p=0.0124)$ (Fig. 5c). 


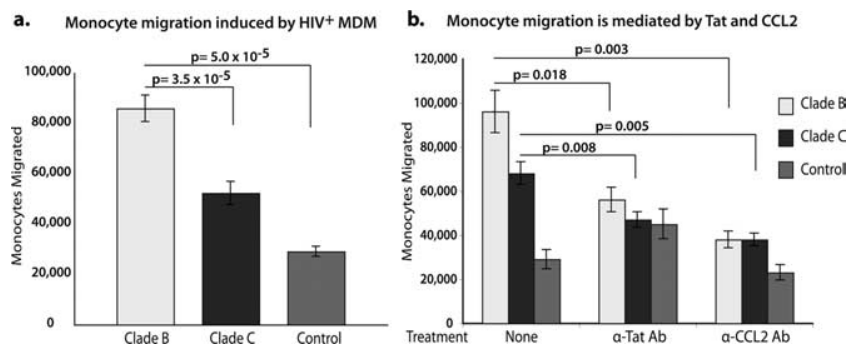

Figure 4. Monocyte migration assays in the presence of HIV-1-infected MDMs using a dualchamber assay. $\boldsymbol{a}$, Monocyte migration caused by clade B and clade C HIV-infected MDMs. The numbers plotted reflect the monocytes detected in the lower chamber by counting the CFSEpositive cells. Numbers plotted represent means from three experiments each (2 quadruplicates and 1 triplicate) $(n=11) . \boldsymbol{b}$, Monocyte migration caused by spent medium from HIV-infected MDMs can be blocked by anti-Tat or anti-CCL2 antibodies. The numbers represent fluorescent cells detected in the lower chamber after $24 \mathrm{~h}$ of incubation. Bars labeled " $\alpha$-Tat $\mathrm{Ab}^{\text {" and }}$ " $\alpha$-CCL2 Ab" represent experiments in which spent media from HIV-infected MDMs were first treated with antibodies as described in Materials and Methods. Numbers plotted represent means from a pentuplicate experiment $(n=5)$. Clade C HIV-infected cells recruit significantly less monocytes than clade B HIV-infected cells, and the monocyte recruitment by the medium from both types of cell is mediated by Tat and CCL2. Error bars represent SEM.

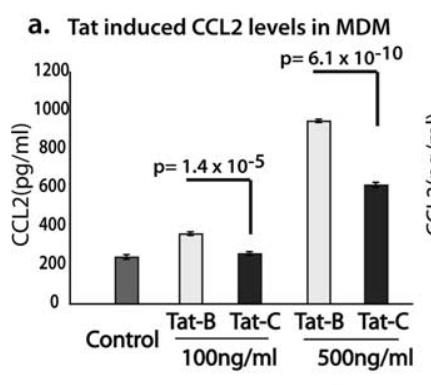

b. Tat induced CCL2 levels in Astrocytes

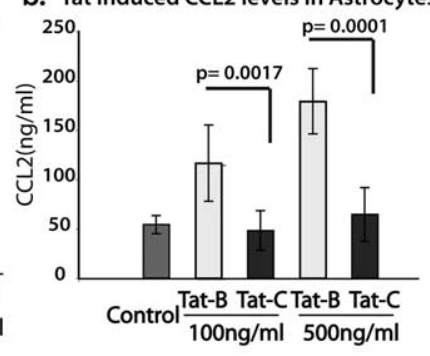

c. HIV-infection induced CCL2 in MDM

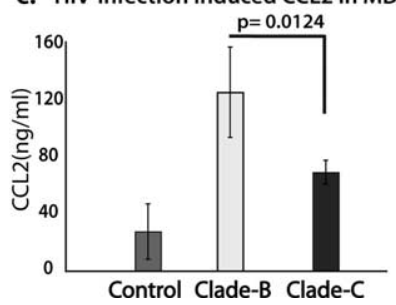

Figure 5. Differential induction of CCL2 by HIV-infected and Tat-treated MDMs and astrocytes (in vitro). $\boldsymbol{a}$, Measurement of CCL2 secreted by MDMs exposed to Tat protein from clade B or clade C HIV-1 at 100 and $500 \mathrm{ng} / \mathrm{ml}$. Control represents cells incubated with untreated medium $(n=6) \cdot \boldsymbol{b}$, Measurement of CCL2 secreted by human astrocytes exposed to Tat protein from clade B or clade C HIV-1 at 100 and $500 \mathrm{ng} / \mathrm{ml}$. Control represents cells incubated with untreated medium $(n=8)$. $c$, Measurement of $C C L 2$ in the media of MDM-infected with clade B or CHIV-1. Control represents uninfected MDMs $(n=6)$. Both Tat treatment and HIV infection of primary MDMs and astrocytes show that clade C HIV-1 is compromised for the induction of CCL2 secretion. Error bars represent SEM.

\section{Discussion}

Reports of reduced prevalence of severe forms HAD in regions with predominantly clade C HIV infections, such as India (Satishchandra et al., 2000; Riedel et al., 2006; Gupta et al., 2007), imply clade-specific differences in neuropathogenesis. To verify this hypothesis, we have used in vitro experiments with purified Tat proteins and in vivo experiments using infectious molecular clones of HIV-1 in the SCID HIVE model. We have extended our previous findings that clade $\mathrm{C}$ Tat is defective in its chemotactic properties. Our results demonstrate, for the first time, differences in neuropathogenesis between clade B and C HIV-1 isolates in an in vivo model. Differential neuropathogenesis observed for the two clades in vivo also correlated with differential ability of HIVinfected MDMs to recruit monocytes in vitro and in inducing chemokines such as CCL2 in infected cells.

Our results revealed significant differences between the two clades in terms of behavioral deficits. Clade B HIVE mice made the most working memory errors and clade C HIVE mice made an intermediate number of errors in reference to clade $\mathrm{B}$ and control mice. Our approach of injecting HIV-infected macrophages into the frontal cortex produces well documented neuropathological and behavioral effects that are widespread rather than limited to the site of injection or right side alone. As described previously (Griffin et al., 2004), multiple areas of the brain are likely involved in causing the behavioral abnormalities, including frontal lobes, hippocampus, and basal ganglia. Some of these affects require a relatively remote action of HIV. These effects are thought to be related to diffusible substances produced by HIV-infected macrophages and activated glia (Griffin et al., 2004). Our behavioral testing protocol does not include WRAM testing of uninoculated normal SCID mice, because they have been previously shown (Avgeropoulos et al., 1998) to perform consistently with, or even better than, our controls injected with uninfected MDMs.

MAP2 staining serves both as a means of measuring HIVinduced damage to neuronal network integrity (Avgeropoulos et al., 1998; Zheng et al., 2001; Dou et al., 2003; O’Donnell et al., 2006) and as a histopathological correlate of HIV-induced behavioral abnormalities (Cook-Easterwood et al., 2007; Sas et al., 2007). Results from analysis of MAP2-stained frontal cortex regions parallel the behavioral findings. Loss of MAP2 staining produced by clade C HIV-1 is intermediate compared with clade $\mathrm{B}$ and control mice. Astrogliosis, a key pathological feature of HAD, was significantly greater $(p=0.0117)$ in clade B HIVE mice than in clade C HIVE mice. Similar numbers of p24-positive cells in the brains and equivalent copy numbers of viral RNA in brain sections of both types of mice confirmed equal viral loads in both cases. These findings not only suggest that clade differences play a major role in pathogenesis of HAD, but also highlight the usefulness of the SCID HIVE mouse model in detecting subtle differences in behavior and histopathology.

More recently it has been shown that direct neurotoxicity of Tat may be mediated by Tat's binding to NMDA receptor subunits NR1 and 2A (A. Nath, personal communication) and that clade $\mathrm{C}$ or a C31S mutant of clade B Tat protein does not cause neurotoxicity (Li et al., 2005), providing an additional explanation for clade differences in NeuroAIDS. The mechanism of toxicity was not mediated by a complex formation among lipoprotein receptor-related protein (LRP), PSD-95, NMDAR (NMDA receptor), and nNOS (neuronal nitric oxide synthase) on the surface of human neurons, as we described previously (Eugenin et al., 2007). It was also not attributable to LRP-mediated Tat internalization, as described in neurons (Liu et al., 2000), because RAP (receptor-associated protein), an LRP blocker, did not abrogate toxicity. These differences in Tat-mediated toxicity may be attributable to the low expression of LRP receptor on HEK cells and the absence of PSD-95 to bridge NMDA receptors and LRP.

Regardless of the precise mechanism of Tat-mediated effects on neurons, our results show that behavioral and neuropathological differences between HIV-1 clades are attributable to an attenuated ability of clade $\mathrm{C}$ Tat to cause neurotoxicity by both direct and indirect mechanisms. Although the studies by A. Nath and colleagues (W. Li, Y. Huang, R. Reid, T. Malpica, J. Steiner, S. Shankar, A. Mahadevan, P. Satishchandra, A. Nath, personal communication) point to clade differences in NMDA receptor- 
mediated apoptosis, Campbell et al. (2007) showed that clade C Tat protein is defective in its ability to generate an intracellular calcium influx and in inducing TNF- $\alpha$, a cytokine that promotes astrogliosis. Additionally, Mishra et al. (2008) has reported lower neurotoxicity, a significantly reduced ROS (reactive oxygen species) induction, and weaker mitochondrial membrane polarization in human neurons by clade $\mathrm{C}$ Tat.

These neurotoxic effects of clade B HIV-1 may have implications for both neuronal and astrocytic dysfunction in HIVE in SCID mice and HAD in humans. The increased astrogliosis seen in HIVE mice with clade B HIV-1 compared with C reflects a larger pool of dysfunctional astrocytes observed (Lipton and Gendelman, 1995). Normally, astrocytes are responsible for clearing excess glutamate at the synaptic cleft to prevent NMDA receptor-mediated excitotoxicity. However, if astrocytes are impaired in this function, it could explain why neurons in the area of greatest astrogliosis display decreased dendritic arborization. In addition, neurotoxicity in clade $\mathrm{B}$ mice could have more direct affects on neurons that are in the vicinity of HIV-infected human MDMs, adding to (indirect) astrocyte affects on neuronal dendritic formation. Therefore, because frontal cortical dendritic formation is important to learned behavior, the clade B mice make a greater number of errors in the WRAM.

Previously, we showed that clade C Tat is defective in monocyte chemotaxis using purified Tat protein in vitro (Ranga et al., 2004) Here, we used HIV-1-infected MDMs for the recruitment of monocytes to demonstrate that monocyte chemotaxis occurs in the setting of virus-infected cells. In comparing the two clades of HIV-1, the differences observed were not caused by differential virus growth. Under these conditions, clade C HIV-infected cells were able to recruit significantly reduced numbers of monocytes compared with clade B HIV-infected MDMs. The SCID HIVE model used here does not allow us to examine whether the differential monocyte chemotaxis observed in vitro applies to monocyte migration across the blood-brain barrier in vivo. Therefore we are looking into developing modified mouse models, in which one can observe the migration of macrophages introduced in the periphery to the sites in brain where HIV-infected macrophages reside under conditions that transiently break down the blood-brain barrier.

In verifying that the monocyte chemotaxis induced by HIVinfected MDMs is truly mediated by Tat protein, we used anti-Tat antibodies with a proven ability to neutralize both clade $\mathrm{B}$ and clade C Tat proteins (Siddappa et al., 2006). Interestingly, neutralizing the Tat protein present in the spent media lowered monocyte migration to control levels, and neutralizing the CCL2 was also effective in blocking monocyte migration, suggesting that Tat or HIV infection induces the secretion of CCL2, which then mediates monocyte migration. These novel findings demonstrate a direct role for Tat during HIV infection of MDMs in monocyte migration. CCL2 is presumably produced as a result of HIV-1 infection. Media from clade C HIV-infected MDMs also showed reduction in the migrating monocytes with anti-Tat and anti-CCL2 antibodies. This reduction was lower than that observed with clade $B$, but statistically significant $(p=008$ for anti-Tat and $p=0.005$ for anti-CCL2).

The ability of clade B HIV-1 Tat protein as well as clade B HIV-1 virus to induce MDMs and astrocytes to secrete CCL2 points to an indirect means by which HIV infection leads to enhanced monocyte infiltration into the brain. We took advantage of the availability of Tat preparations that were equally biologically active in their ability to be taken up by cells and to activate HIV-1 LTR-mediated expression of a GFP reporter (Sid- dappa et al., 2006). Despite their similar activities (Siddappa et al., 2006), there were significant differences in CCL2 induction by the two different Tat proteins when incubated with primary astrocytes or MDMs. These differences were also observed between MDMs infected with the two clades of HIV-1. The differential induction of CCL2 by the two Tat proteins and by infection with the two clades of HIV-1 suggests another key difference between the clades in the pathogenesis of HAD.

Our results demonstrate that genotypic differences between HIV-1 clade B and clade $\mathrm{C}$ viruses do translate to phenotype differences in HAD pathogenesis outcomes in vivo by virtue of decreased direct neurotoxicity of clade C HIV-1 as well as lead to differences observable in vitro, including defective monocyte migration and the impaired secretion of chemotactic proteins such as CCL2. Our results provides a concrete proof of interclade differences and hope that specific HIV genes directly involved in neuropathogenesis can be pinpointed by the use of chimeric viruses between clades, work on which is currently being pursued in our laboratory. The findings reported here may have significant implications for future treatment strategies in HAD by helping target specific genes responsible for pathogenesis of HAD.

\section{References}

Albini A, Benelli R, Giunciuglio D, Cai T, Mariani G, Ferrini S, Noonan DM (1998) Identification of a novel domain of HIV tat involved in monocyte chemotaxis. J Biol Chem 273:15895-15900.

Avgeropoulos N, Kelley B, Middaugh L, Arrigo S, Persidsky Y, Gendelman HE, Tyor WR (1998) SCID mice with HIV encephalitis develop behavioral abnormalities. J Acquir Immune Defic Syndr Hum Retrovirol 18:13-20.

Bimonte-Nelson HA, Hunter CL, Nelson ME, Granholm AC (2003) Frontal cortex BDNF levels correlate with working memory in an animal model of Down syndrome. Behav Brain Res 139:47-57.

Campbell GR, Watkins JD, Singh KK, Loret EP, Spector SA (2007) Human immunodeficiency virus type 1 subtype $\mathrm{C}$ Tat fails to induce intracellular calcium flux and induces reduced tumor necrosis factor production from monocytes. J Virol 81:5919-5928.

Chakrabarti S, Panda S, Chatterjee A, Sarkar S, Manna B, Singh NB, Naik TN, Detels R, Bhattacharya SK (2000) HIV-1 subtypes in injecting drug users and their non-injecting wives in Manipur, India. Indian J Med Res 111:189-194.

Conant K, Garzino-Demo A, Nath A, McArthur JC, Halliday W, Power C, Gallo RC, Major EO (1998) Induction of monocyte chemoattractant protein-1 in HIV-1 Tat-stimulated astrocytes and elevation in AIDS dementia. Proc Natl Acad Sci U S A 95:3117-3121.

Cook JE, Dasgupta S, Middaugh LD, Terry EC, Gorry PR, Wesselingh SL, Tyor WR (2005) Highly active antiretroviral therapy and human immunodeficiency virus encephalitis. Ann Neurol 57:795-803.

Cook-Easterwood J, Middaugh LD, Griffin WC 3rd, Khan I, Tyor WR (2007) Highly active antiretroviral therapy of cognitive dysfunction and neuronal abnormalities in SCID mice with HIV encephalitis. Exp Neurol 205:506-512.

D’Aversa TG, Yu KO, Berman JW (2004) Expression of chemokines by human fetal microglia after treatment with the human immunodeficiency virus type 1 protein Tat. J Neurovirol 10:86-97.

Dore GJ, McDonald A, Li Y, Kaldor JM, Brew BJ (2003) Marked improvement in survival following AIDS dementia complex in the era of highly active antiretroviral therapy. AIDS 17:1539-1545.

Dou H, Birusingh K, Faraci J, Gorantla S, Poluektova LY, Maggirwar SB, Dewhurst S, Gelbard HA, Gendelman HE (2003) Neuroprotective activities of sodium valproate in a murine model of human immunodeficiency virus-1 encephalitis. J Neurosci 23:9162-9170.

Eugenin EA, Osiecki K, Lopez L, Goldstein H, Calderon TM, Berman JW (2006) CCL2/monocyte chemoattractant protein-1 mediates enhanced transmigration of human immunodeficiency virus (HIV)-infected leukocytes across the blood-brain barrier: a potential mechanism of HIV-CNS invasion and NeuroAIDS. J Neurosci 26:1098-1106.

Eugenin EA, King JE, Nath A, Calderon TM, Zukin RS, Bennett MV, Berman JW (2007) HIV-tat induces formation of an LRP-PSD-95- NMDAR- 
nNOS complex that promotes apoptosis in neurons and astrocytes. Proc Natl Acad Sci U S A 104:3438-3443.

Geretti AM (2006) HIV-1 subtypes: epidemiology and significance for HIV management. Curr Opin Infect Dis 19:1-7.

Gourdou I, Mabrouk K, Harkiss G, Marchot P, Watt N, Hery F, Vigne R (1990) Neurotoxicity in mice due to cysteine-rich parts of visna virus and HIV-1 Tat proteins. C R Acad Sci III 311:149-155.

Griffin WC 3rd, Middaugh LD, Cook JE, Tyor WR (2004) The severe combined immunodeficient (SCID) mouse model of human immunodeficiency virus encephalitis: deficits in cognitive function. J Neurovirol 10:109-115.

Gupta JD, Satishchandra P, Gopukumar K, Wilkie F, Waldrop-Valverde D, Ellis R, Ownby R, Subbakrishna DK, Desai A, Kamat A, Ravi V, Rao BS, Satish KS, Kumar M (2007) Neuropsychological deficits in human immunodeficiency virus type 1 clade C-seropositive adults from South India. J Neurovirol 13:195-202.

Hunter CL, Bimonte-Nelson HA, Nelson M, Eckman CB, Granholm AC (2004) Behavioral and neurobiological markers of Alzheimer's disease in Ts65Dn mice: effects of estrogen. Neurobiol Aging 25:873-884.

Hyde LA, Hoplight BJ, Denenberg VH (1998) Water version of the radialarm maze: learning in three inbred strains of mice. Brain Res $785: 236-244$.

Jarrard LE (1993) On the role of the hippocampus in learning and memory in the rat. Behav Neural Biol 60:9-26.

Langford TD, Letendre SL, Larrea GJ, Masliah E (2003) Changing patterns in the neuropathogenesis of HIV during the HAART era. Brain Pathol 13:195-210.

Li W, Galey D, Mattson MP, Nath A (2005) Molecular and cellular mechanisms of neuronal cell death in HIV dementia. Neurotox Res 8:119-134.

Lipton SA, Gendelman HE (1995) Dementia associated with the acquired immunodeficiency syndrome. Seminars in medicine of the Beth Israel Hospital, Boston. N Engl J Med 332:934-940.

Liu Y, Jones M, Hingtgen CM, Bu G, Laribee N, Tanzi RE, Moir RD, Nath A, He JJ (2000) Uptake of HIV-1 tat protein mediated by low-density lipoprotein receptor-related protein disrupts the neuronal metabolic balance of the receptor ligands. Nat Med 6:1380-1387.

Mahadevan A, Shankar SK, Satishchandra P, Ranga U, Chickabasaviah YT, Santosh V, Vasanthapuram R, Pardo CA, Nath A, Zink MC (2007) Characterization of human immunodeficiency virus (HIV)-infected cells in infiltrates associated with CNS opportunistic infections in patients with HIV clade C infection. J Neuropathol Exp Neurol 66:799-808.

McArthur JC, Hoover DR, Bacellar H, Miller EN, Cohen BA, Becker JT, Graham NM, McArthur JH, Selnes OA, Jacobson LP, Visscher BR, Concha M, Saah A (1993) Dementia in AIDS patients: incidence and risk factors. Neurology 43:2245-2252.

Mishra M, Vetrivel S, Siddappa NB, Ranga U, Seth P (2008) Clade-specific differences in neurotoxicity of human immunodeficiency virus- $1 \mathrm{~B}$ and $\mathrm{C}$ Tat of human neurons: significance of dicysteine C30C31 motif. Ann Neurol 63:366-376.

Mochizuki N, Otsuka N, Matsuo K, Shiino T, Kojima A, Kurata T, Sakai K, Yamamoto N, Isomura S, Dhole TN, Takebe Y, Matsuda M, Tatsumi M (1999) An infectious DNA clone of HIV type 1 subtype C. AIDS Res Hum Retroviruses 15:1321-1324

O'Donnell LA, Agrawal A, Jordan-Sciutto KL, Dichter MA, Lynch DR, Kolson DL (2006) Human immunodeficiency virus (HIV)-induced neurotoxicity: roles for the NMDA receptor subtypes. J Neurosci 26:981-990.

Persidsky Y, Limoges J, McComb R, Bock P, Baldwin T, Tyor W, Patil A,
Nottet HS, Epstein L, Gelbard H, Flanagan E, Reinhard J, Pirruccello SJ, Gendelman HE (1996) Human immunodeficiency virus encephalitis in SCID mice. Am J Pathol 149:1027-1053.

Persidsky Y, Buttini M, Limoges J, Bock P, Gendelman HE (1997) An analysis of HIV-1-associated inflammatory products in brain tissue of humans and SCID mice with HIV-1 encephalitis. J Neurovirol 3:401-416.

Ranga U, Shankarappa R, Siddappa NB, Ramakrishna L, Nagendran R, Mahalingam M, Mahadevan A, Jayasuryan N, Satishchandra P, Shankar SK, Prasad VR (2004) Tat protein of human immunodeficiency virus type 1 subtype C strains is a defective chemokine. J Virol 78:2586-2590.

Rao VR, Eugenin EA, Berman JW, Prasad VR (2009) Methods to study monocyte migration induced by HIV-infected cells. In: HIV protocols (Prasad VR, Kalpana GV, eds). New York: Springer.

Riedel D, Ghate M, Nene M, Paranjape R, Mehendale S, Bollinger R, Sacktor N, McArthur J, Nath A (2006) Screening for human immunodeficiency virus (HIV) dementia in an HIV clade C-infected population in India. J Neurovirol 12:34-38.

Sabatier JM, Vives E, Mabrouk K, Benjouad A, Rochat H, Duval A, Hue B, Bahraoui E (1991) Evidence for neurotoxic activity of tat from human immunodeficiency virus type 1. J Virol 65:961-967.

Sacktor N, Lyles RH, Skolasky R, Kleeberger C, Selnes OA, Miller EN, Becker JT, Cohen B, McArthur JC, Multicenter AIDS Cohort Study (2001) HIV-associated neurologic disease incidence changes: Multicenter AIDS Cohort Study, 1990-1998. Neurology 56:257-260.

Sas AR, Bimonte-Nelson HA, Tyor WR (2007) Cognitive dysfunction in HIV encephalitic SCID mice correlates with levels of interferon- $\alpha$ in the brain. AIDS 21:2151-2159.

Satishchandra P, Nalini A, Gourie-Devi M, Khanna N, Santosh V, Ravi V, Desai A, Chandramuki A, Jayakumar PN, Shankar SK (2000) Profile of neurologic disorders associated with HIV/AIDS from Bangalore, south India (1989-96). Indian J Med Res 111:14-23.

Schwarze SR, Ho A, Vocero-Akbani A, Dowdy SF (1999) In vivo protein transduction: delivery of a biologically active protein into the mouse. Science 285:1569-1572.

Siddappa NB, Dash PK, Mahadevan A, Jayasuryan N, Hu F, Dice B, Keefe R, Satish KS, Satish B, Sreekanthan K, Chatterjee R, Venu K, Satishchandra P, Ravi V, Shankar SK, Shankarappa R, Ranga U (2004) Identification of subtype $C$ human immunodeficiency virus type 1 by subtype-specific PCR and its use in the characterization of viruses circulating in the southern parts of India. J Clin Microbiol 42:2742-2751.

Siddappa NB, Venkatramanan M, Venkatesh P, Janki MV, Jayasuryan N, Desai A, Ravi V, Ranga U (2006) Transactivation and signaling functions of Tat are not correlated: biological and immunological characterization of HIV-1 subtype-C Tat protein. Retrovirology 3:53.

Tyor WR, Power C, Gendelman HE, Markham RB (1993) A model of human immunodeficiency virus encephalitis in scid mice. Proc Natl Acad Sci U S A 90:8658-8662.

Weiss JM, Nath A, Major EO, Berman JW (1999) HIV-1 Tat induces monocyte chemoattractant protein-1-mediated monocyte transmigration across a model of the human blood-brain barrier and up-regulates CCR5 expression on human monocytes. J Immunol 163:2953-2959.

Zheng J, Thylin MR, Cotter RL, Lopez AL, Ghorpade A, Persidsky Y, Xiong H, Leisman GB, Che MH, Gendelman HE (2001) HIV-1 infected and immune competent mononuclear phagocytes induce quantitative alterations in neuronal dendritic arbor: relevance for HIV-1-associated dementia. Neurotox Res 3:443-459. 